\title{
The Mohr-Coulomb criterion for intact rock strength and friction - a re-evaluation and consideration of failure under polyaxial stresses
}

\author{
Abigail Hackston ${ }^{1, \mathrm{a}}$ and Ernest Rutter ${ }^{1}$ \\ ${ }^{1}$ Rock Deformation Laboratory, School of Earth and Environmental Sciences, University of Manchester, \\ Manchester M13 9PL, UK \\ ${ }^{\text {a }}$ now at: Ove Arup, Admiral House, 78 East street, Leeds, LS9 8EE, UK \\ Correspondence to: Ernest Rutter (e.rutter@manchester.ac.uk)
}

Received: 28 November 2015 - Published in Solid Earth Discuss.: 18 December 2015

Revised: 10 March 2016 - Accepted: 14 March 2016 - Published: 1 April 2016

\begin{abstract}
Darley Dale and Pennant sandstones were tested under conditions of both axisymmetric shortening and extension normal to bedding. These are the two extremes of loading under polyaxial stress conditions. Failure under generalized stress conditions can be predicted from the MohrCoulomb failure criterion under axisymmetric shortening conditions, provided the best form of polyaxial failure criterion is known. The sandstone data are best reconciled using the Mogi (1967) empirical criterion. Fault plane orientations produced vary greatly with respect to the maximum compressive stress direction in the two loading configurations. The normals to the Mohr-Coulomb failure envelopes do not predict the orientations of the fault planes eventually produced. Frictional sliding on variously inclined saw cuts and failure surfaces produced in intact rock samples was also investigated. Friction coefficient is not affected by fault plane orientation in a given loading configuration, but friction coefficients in extension were systematically lower than in compression for both rock types. Friction data for these and other porous sandstones accord well with the Byerlee (1978) generalization about rock friction being largely independent of rock type. For engineering and geodynamic modelling purposes, the stress-state-dependent friction coefficient should be used for sandstones, but it is not known to what extent this might apply to other rock types.
\end{abstract}

\section{Introduction}

The Mohr-Coulomb failure criterion is widely applied to the description of intact rock failure and to the description of rock-on-rock frictional sliding (e.g. Byerlee, 1978; Al-Ajmi and Zimmerman, 2006; Rutter and Glover, 2012). It assumes that failure occurs at particular combinations of the greatest and least principal stresses, that the intermediate principal stress has no effect on failure and that failure criteria can be set out in terms only of the stress state, without any consideration of the state of strain or the deformation mechanisms at work that lead to failure. It is easy to adapt to many geomechanical modelling problems and it is widely applied to problems that involve polyaxial loading (e.g. Vernik and Zoback, 1992; Castillo et al., 2000), often because nothing otherwise is known about the behaviour of particular rocks under polyaxial stress conditions. There are many applications that demand knowledge of failure or frictional sliding under generalized stress conditions. These include modelling reservoir or cap rock behaviour, or the estimation of far-field stresses from borehole breakout geometry, but the uncritical application a Mohr-Coulomb failure criterion based on only uniaxially symmetric shortening experiments can result in significant errors (Song and Haimson, 1997).

Experiments on the strength of two porous sandstones and on the orientation of the fault plane produced are described here to evaluate the generality of the Mohr-Coulomb criterion under the extreme conditions of axially symmetric shortening and axially symmetric extension. In the former, the intermediate principal stress $\sigma_{2}$ equals the least principal stress $\sigma_{3}$, and in the latter instance the intermediate principal 


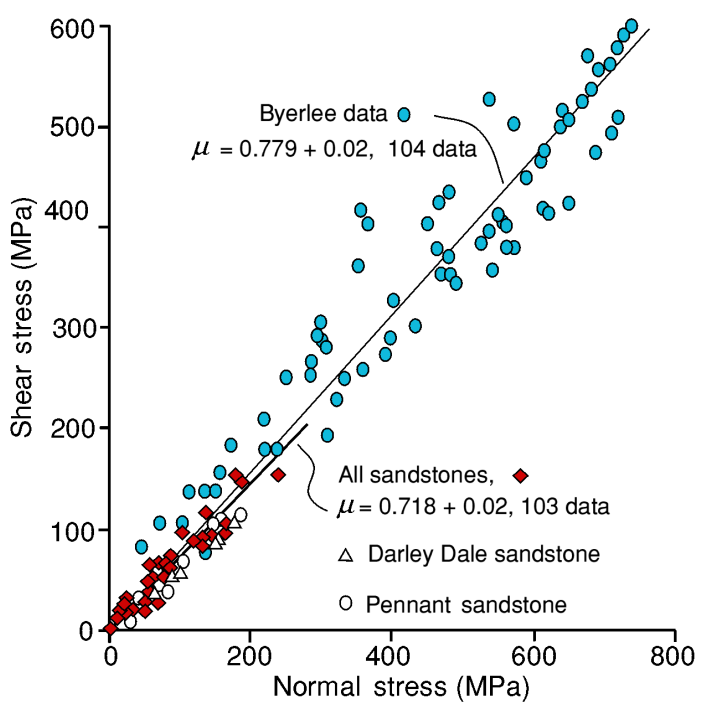

Figure 1. Compilation of friction data for (mainly crystalline) rocks up to a normal stress of $800 \mathrm{MPa}$ by Byerlee (1978). In this pressure range there is no basis for recognizing two pressure regimes represented by different friction coefficients. Data are also shown for various other sandstones, from Rutter (for Berea sandstone, unpublished), Menéndez et al. (1996), Mair and Marone (1999), Numelin et al. (2007) and Scott and Nielsen (1991a, b), plus Pennant and Darley Dale sandstones (this study). Collectively, the sandstones display a slightly lower friction coefficient $(0.718)$ than the crystalline rocks (0.779).

stress equals the greatest principal stress $\sigma_{1}$. Colmenares and Zoback (2002) compared a number of different failure criteria using published experimental data obtained under polyaxial stress conditions, but with $\sigma_{2}$ closer to $\sigma_{3}$ than to $\sigma_{1}$. These results served to show that variations in the magnitude of $\sigma_{2}$ can significantly affect failure and the criteria used to describe it, but they also emphasize the increasing sensitivity of results to the magnitude of $\sigma_{2}$ as $\sigma_{2}$ approaches $\sigma_{1}$ and, hence, the importance of obtaining data that extends to include the axisymmetric extension end-member condition.

Rock-on-rock sliding friction is defined in terms of the effective stress normal to the sliding surface and to the shear stress resolved in the direction in which sliding occurs (Byerlee, 1968, 1978). It is therefore a 2-D criterion and friction is generally assumed not to depend on the intermediate principal stress. Rock-on-rock sliding friction is important to geomechanical modelling because it limits the differential stresses that can be obtained at any given depth in the upper crust of the Earth. From a compilation of friction data for a wide range of rock types, Byerlee (1978) suggested that it is a property that is, to a useful approximation, independent of rock type (Fig. 1). These characteristics of friction as a rock property have been widely applied to developing understanding of crustal stresses and rock rheology (e.g. Goetze and Evans, 1979; Kohlstedt et al., 1995; Zoback, 2007). To test these generalizations, frictional measurements were therefore made on these same two sandstones under both axially extensional and compressional loading configurations and with variously oriented saw cuts made in the rock cylinder.

\section{Rock types and experiments performed}

Two quartz sandstones of different porosities were used.

The first, Pennant sandstone, is an Upper Carboniferous quartz sandstone from South Wales (Kelling, 1974). This grey, durable rock is available from stone merchants in large homogeneous blocks and is used as a kerbstone and paving stone. Modal composition (by chemical mapping on the scanning electron microscope) is $70 \%$ sutured quartz grains and $15 \%$ feldspar; interstices between these grains are filled with clusters of muscovite, oxides and clay minerals, with a small amount of remaining porosity, $4.57 \% \pm 0.23 \%$ (1 standard deviation, SD). Porosity was determined both by gravimetry and helium porosimetry. Quartz grain size (Fig. 2a) is $200 \pm 90 \mu \mathrm{m}$ (1 SD). Bedding traces are hard to detect (Fig. 2a).

The second, Darley Dale sandstone, is an Upper Carboniferous quartz sandstone from Derbyshire, England. This yellow decorative stone has previously been widely used in rock mechanics investigations (e.g. Zhu and Wong, 1997; Heap et al., 2009 amongst others). It is available from stone merchants as large, homogeneous blocks. It consists of $67 \%$ quartz, $16 \%$ feldspar and 3\% detrital muscovite and clay minerals. Porosity is $13.5 \% \pm 1 \%$. Bedding is only weakly apparent in the block used. Quartz grain size (Fig. 2b) varies widely $400 \pm 250 \mu \mathrm{m}$.

The permeability $k\left(\mathrm{~m}^{2}\right)$ of Darley Dale sandstone to water, normal to bedding, was reported by Zhu and Wong (1997) and is sensitive to effective confining pressure $P e(\mathrm{MPa}$, defined as confining pressure - pore pressure), given by

$\log (k)=-0.878 \log (P e)-12.8$.

Thus permeability decreases from $10^{-13.2} \mathrm{~m}^{2}$ at $3 \mathrm{MPa}$ effective pressure to $10^{-14.6} \mathrm{~m}^{2}$ at $100 \mathrm{MPa}$ effective pressure.

The permeability of Pennant sandstone to argon gas was measured normal to bedding during the course of the present study using the oscillating pore pressure method (Bernabé et al., 2006) over the effective pressure range 1 to $70 \mathrm{MPa}$ and is much lower than that of Darley Dale sandstone. It is best described by

$\log k=-0.0113 P e-18.2$.

Thus permeability decreases from about $10^{-18.2}$ to $10^{-19} \mathrm{~m}^{2}$ over an effective pressure range from 1 to $70 \mathrm{MPa}$. Effective pressure change produced by varying pore pressure at constant confining pressure has the same effect on permeability as changing confining pressure at constant pore pressure. The 


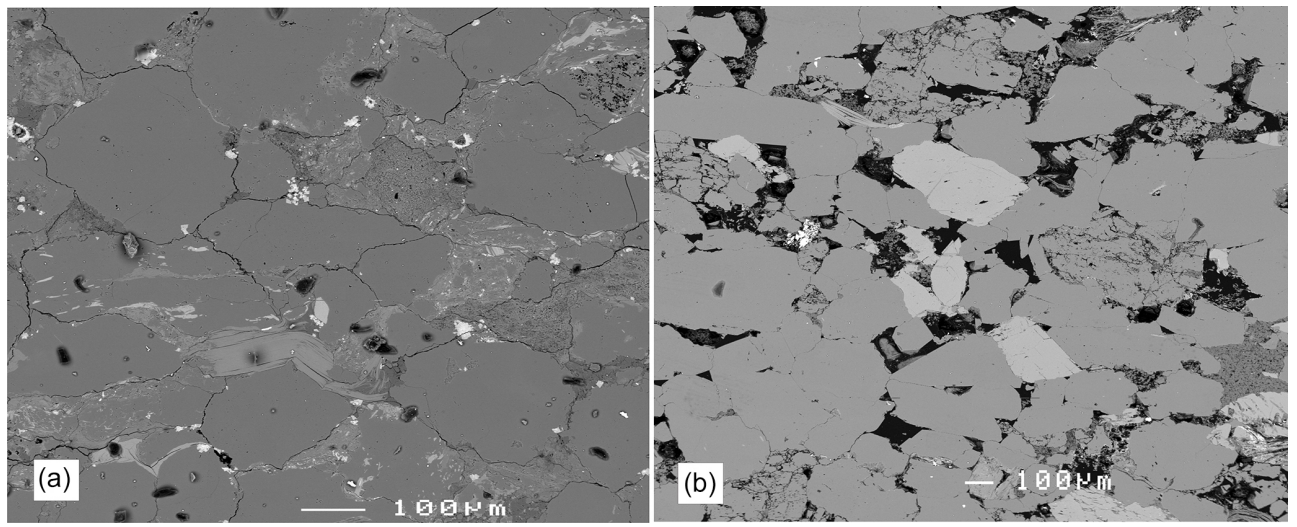

Figure 2. Back-scattered electron images showing microstructure of (a) Pennant and (b) Darley Dale sandstones. Both rocks are dominated by quartz grains (mid-grey). Clay and muscovite partially (b) or wholly (a) fill interstitial spaces. There is a weak grain shape fabric (grain long axes horizontal) in the Pennant sandstone. Porosity appears black. Bedding trace is horizontal in both cases.

permeability of this rock is as low as that of many shales - it is a tight sandstone - and this is an important consideration if pore fluid pressure is applied. The porosity differences have a major impact on the relative cohesive strengths of these rocks.

As part of specimen characterization, acoustic velocity measurements were made under unconfined conditions normal $\left(V_{\mathrm{c}}\right)$ and parallel $\left(V_{\mathrm{a}}\right)$ to bedding. The Darley Dale sandstone was nearly isotropic $\left(V_{\mathrm{c}}=2.72 \mathrm{~km} \mathrm{~s}^{-1} ; V_{\mathrm{a}}=\right.$ $2.71 \mathrm{~km} \mathrm{~s}^{-1}$ ) but the Pennant sandstone displayed a velocity anisotropy of $7.5 \%\left(V_{\mathrm{c}}=2.91 \mathrm{~km} \mathrm{~s}^{-1} ; V_{\mathrm{a}}=3.38 \mathrm{~km} \mathrm{~s}^{-1}\right)$. In both cases there was no significant velocity variation in the plane of bedding (transverse isotropy). Anisotropy is expected to decrease with increasing confining pressure, and acoustic anisotropy does not necessarily correlate with strength anisotropy, which was not investigated during the course of this study.

For mechanical tests, cores of either 20 or $15 \mathrm{~mm}$ nominal diameter were taken normal to bedding from both rocks and ground to a length: diameter ratio of $2.5: 1$. For tests on rock-on-rock frictional sliding on saw cuts, inclined planar cuts were made across samples at either 35,45 or $55^{\circ}$ to the cylinder axis, and the surfaces were ground to a $16 \mu \mathrm{m}$ surface finish. Prepared samples were dried and kept in an oven at $60^{\circ} \mathrm{C}$ until use. All tests reported were performed in this dried state without pore pressure, and all tests on saw cut specimens were performed without any fault gouge in the sliding plane.

Samples were jacketed in an inner sleeve, $3 \mathrm{~mm}$ thick, of soft silicone rubber and an outer sealing jacket of heat-shrink tubing. Tests were carried out that showed the jacketing arrangements did not support any significant differential stress ( $0.1 \mathrm{MPa}$ or less). To permit testing in extension, a bayonet connector was used on the lower loading piston to allow the axial load to be reduced as the upper loading piston was withdrawn (Fig. 3). This arrangement was first described and used

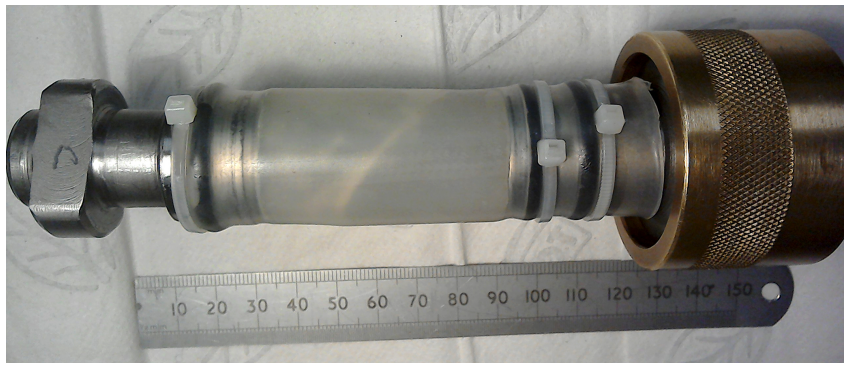

Figure 3. A jacketed sample with a $45^{\circ}$ pre-cut. Around the sample is a $3 \mathrm{~mm}$ (wall thickness) soft silicone rubber sleeve to minimize the risk of the sliding parts puncturing the outer jacket that seals against ingress of confining pressure fluid. On the left is the bayonet connector that allows samples to be tested in axisymmetric extension as well as in axisymmetric shortening. Scale divisions are $1 \mathrm{~cm}$.

by Heard $(1960,1963,1972)$. Thus specimens are tested in axisymmetric extension (not tension), in which the radial hydrostatic confining pressure provides the maximum (and intermediate) principal stresses, and the axial stress becomes $\sigma_{3}$.

The apparatus used employs a synthetic hydraulic oil (Reolube DOS synthetic ester) whose viscosity is relatively insensitive to hydrostatic pressure over a range of more than $400 \mathrm{MPa}$. Axial load was measured using an internal load cell that permitted stress measurements to an accuracy of better than 0.5 MPa. Axial loading and confining pressure regulation was achieved by computer-controlled electromechanical servo-systems.

As a means of testing rock frictional sliding, the use of an inclined saw cut is imperfect. If confining pressure is kept constant and axial load is increased, as the resolved shear stress increases so too does the resolved normal stress. This means that any tendency towards displacement hardening during sliding will be exacerbated, and the shear and nor- 

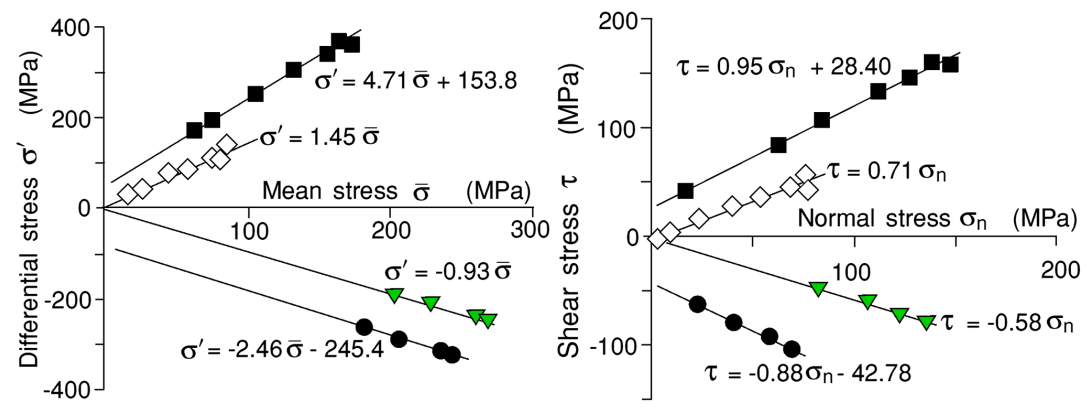

(a) Pennant sandstone

(b) Darley Dale sandstone

$$
\begin{gathered}
\text { Shortening Extension } \\
\qquad \text { Ultimate strength } \bullet \\
\diamond \text { Frictional strength } \nabla
\end{gathered}
$$
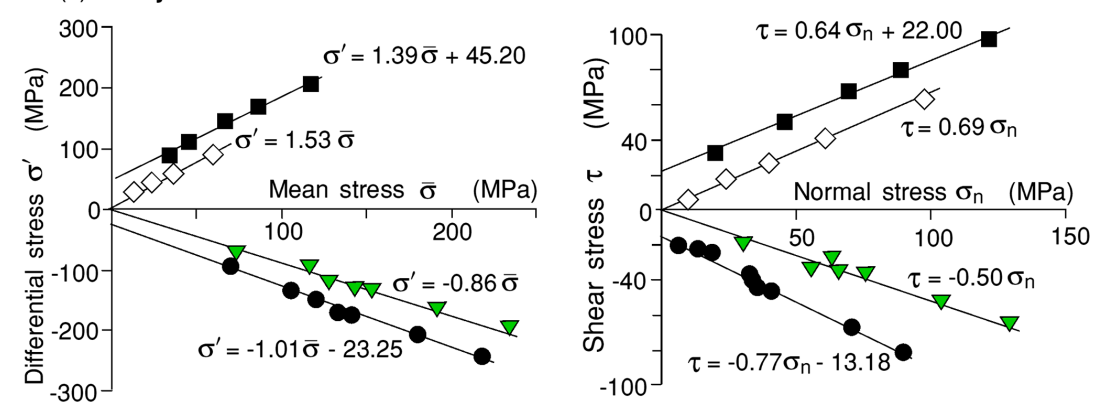

Figure 4. Summary of results of experiments on intact rock cylinders in axisymmetric extension and shortening, for ultimate strength and residual strength (frictional sliding on fault plane formed). Data are shown as differential stress versus mean stress and as resolved normal and shear stress on the fault plane orientation for each rock type. Shear stress and differential stress are shown as negative for extension tests. Errors of measurement are generally smaller than the size of the points plotted.

mal stresses will migrate along the frictional sliding line as the test progresses. The problem can be overcome by servocontrolling the confining pressure so that the resolved normal stress on the slip surface is kept constant. This was done in the most of the present experiments.

A second problem is that the displacement of the two halves of the specimen changes the surface area of contact across the slip plane. Opinions vary about how to deal with this effect, but if friction is measured at 0 or small displacement of the forcing blocks relative to each other, the effect is minimized. This is feasible particularly in the case of sliding tests on $45^{\circ}$ saw cut specimens, because the specimen can be slid back and forth many times under constant resolved normal stress, and the shear stress can be measured at the zero displacement point when the whole slip plane area is in contact with its other half.

A third problem is that sideways displacement of the specimen halves induces a bending moment in the axial column, which increases both the normal and shear stress resolved across and along the slip surface. The problem was analysed by Mackwell and Paterson (2002). The additional lateral force across the specimen, $P$, as a result of elastic flexure of the axial column of diameter $d$ and length $L$ is given by

$P=3 \pi s \sin (\theta) E d^{4} /\left(128 L^{3}\right)$, in which $s$ is the shearing displacement on a shear surface inclined at angle $\theta$ to the maximum compressive stress and $E$ is the Young's modulus of the column. This can be resolved as an additional normal and shear stress acting across and parallel to the sliding surface. In the apparatus used this is expected to have only a small effect on the stresses on the sample, but the effect can be minimized if friction is measured at close to zero slip offset.

\section{Experimental results}

The results of all mechanical tests are summarized in Tables 1 and 2. Intact cylinders of both sandstones were tested until shear failure both in axisymmetric extension and in shortening, and displacement was continued so that the resistance to frictional sliding on the fault plane produced could be established. A second suite of tests was performed on saw cut samples to determine friction coefficients in both extension and shortening.

\subsection{Tests on intact rock cylinders}

Figure 4 shows results for intact cylinders in extension and shortening for both rock types, as differential stress at failure versus mean stress (to permit meaningful comparison between shortening and extension tests) and also as shear 

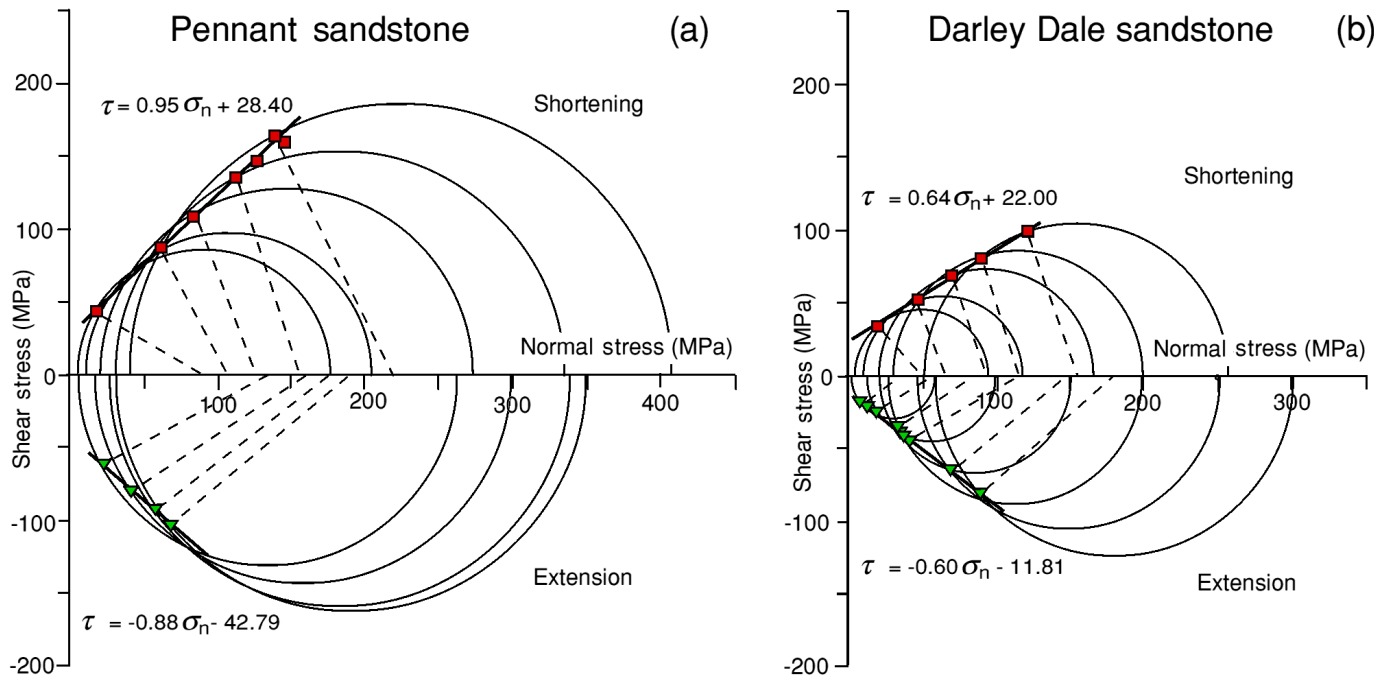

(b)

Figure 5. Some of the results for ultimate strength of Pennant and Darley Dale sandstones in extension and shortening expressed as Mohr circles at failure. Also shown are resolved normal and shear stresses at the point of failure on the fault planes that formed, the orientations of which are half of the angle subtended by the dashed lines with the abscissa. The Mohr envelopes are not shown, but they would lie at higher stresses than the best fits to the resolved stresses on the incipient fault planes. Fault angles are systematically larger in shortening than in extension, and the angles subtended by the normals to the Mohr envelopes are approximately half-way between these extremes.
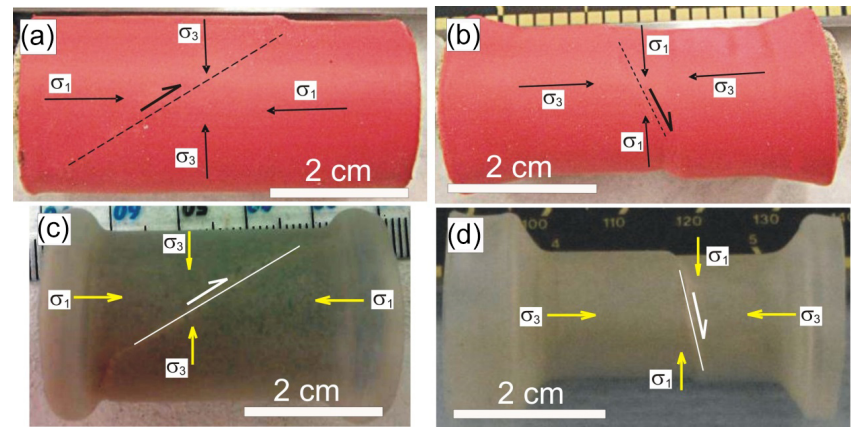

Figure 6. Photographs of fresh faults in shortened cylinders of (a) Darley Dale sandstone (DDa18 at $30 \mathrm{MPa}$ confining pressure), (c) Pennant sandstone Pen23 at $40 \mathrm{MPa}$ and extended cylinders (b) Darley Dale sandstone DDa19 at $250 \mathrm{MPa}$ and (d) Pennant sandstone Pen38 at $300 \mathrm{MPa}$ confining pressure. Samples are still in their heat-shrink rubber jackets. Fault planes and shear senses are indicated. In shortened samples faults make larger angles with the maximum stress than in extended samples.

stress resolved along the plane of the fault produced versus resolved normal stress. Figure 5 shows experimental results for intact rock failure expressed as Mohr circles and also compared to shear stress at peak strength resolved along the fault plane produced versus resolved normal stress. The angles of the fault planes produced, with respect to $\sigma_{1}$ (Figs. 5 and 6), are systematically larger in shortening than in extension. The failure envelope defined by the peak resolved normal and shear stress on the fault planes produced lies slightly lower than that defined by the envelope of the Mohr circles
(Fig. 5). Thus the normal to the Mohr envelope does not successfully predict the fault plane angles, but the predicted fault angle lies somewhere between the extremes of the fault angles actually produced in shortening and extension. Figure 4 also shows that the coefficient of friction on freshly produced fault surfaces is smaller in extension than in shortening for both rock types. For Pennant and Darley Dale sandstones it is 0.71 and 0.89 in compression and 0.58 and 0.50 in extension respectively, both \pm 0.01 .

Preparatory to the formation of the fault plane, intact rock samples tend to develop arrays of intragranular cracks that form parallel to maximum compressive stress. To determine whether some systematic refraction of $\sigma_{1}$ might explain the different orientations of the fault planes in extension and shortening, axial crack orientations were mapped on photomicrograph composites. Examples are shown in Fig. 7 for extended and shortened samples. Maximum principal stress trajectories in shortening tend to remain parallel to the specimen length, whilst refraction of $\sigma_{1}$ trajectories towards the fault plane develops in extended samples (Fig. 7). This is counter-intuitive and does not explain the differences in fault plane orientations between extension and shortening. The same effect has previously been reported by Mogi (1971) and later in a more comprehensive study by Haimson and Rudnicki (2010), who were able to explore it over a wider range of polyaxial stress states.

\subsection{Tests on saw cut samples}

Where possible, saw cut samples were tested both in extension and shortening. There was no difference in the fric- 

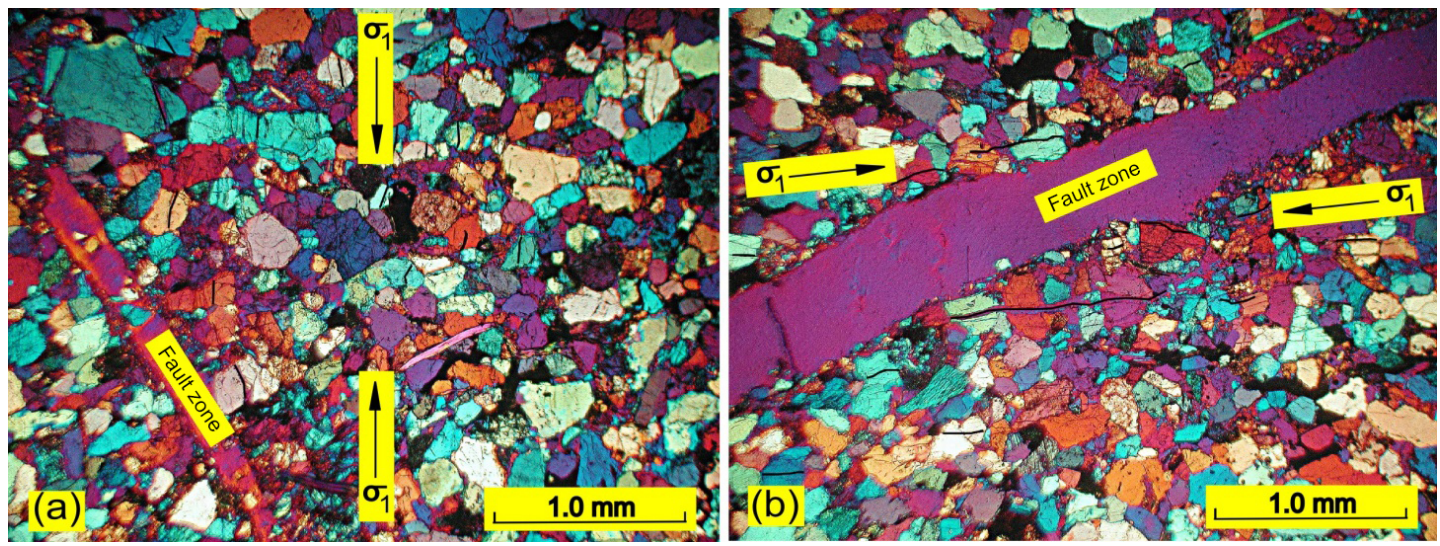

Figure 7. Optical photomicrographs (crossed polars with gypsum plate) of faulted, initially intact samples of Darley Dale sandstone (a) DDa9 (30 MPa confining pressure, shortening) and (b) DDa13 (170 MPa confining pressure, extension). In each case the cylinder long axis is vertical and intensely granulated material has been lost from the fault zone in the sectioning process. Axial transgranular extension cracks have formed in the grains adjacent to the fault zone and these reveal the local orientation of maximum compressive stress $\sigma_{1}$. In (a) the $\sigma_{1}$ direction remains parallel to the cylinder axis, at a high angle to the fault plane. In (b) the $\sigma_{1}$ direction is locally refracted towards the fault plane, which makes a relatively small angle with the far-field $\sigma_{1}$ direction.

Table 1. Tests on intact rock cylinders. Fault angle is measured from cylinder axis. Axial displacement rate is $0.05 \mathrm{~mm} \mathrm{~min}^{-1}$. Shear stresses are negative in extension.

\begin{tabular}{|c|c|c|c|c|c|c|c|}
\hline \multirow[t]{2}{*}{ Test \# } & \multirow{2}{*}{$\begin{array}{l}\text { Test type } \\
\text { comp/ext }\end{array}$} & \multirow{2}{*}{$\begin{array}{l}\text { Fault } \\
\text { angle }\end{array}$} & \multicolumn{2}{|c|}{ Principal stresses at failure } & \multicolumn{2}{|c|}{ Frictional sliding stress } & \multirow{2}{*}{$\begin{array}{r}\text { Friction } \\
\text { coeff. }\end{array}$} \\
\hline & & & $\operatorname{Max}(\mathrm{MPa})$ & Min (MPa) & Normal (MPa) & Shear (MPa) & \\
\hline \multicolumn{8}{|c|}{ Pennant sandstone } \\
\hline Pen4 & comp & 31 & 412.5 & 50 & 75.4 & 42.3 & 0.561 \\
\hline Pen5 & comp & 31 & 335 & 30 & 52.3 & 37.1 & 0.709 \\
\hline Pen6 & comp & 30 & 274 & 20 & 39 & 32.9 & 0.844 \\
\hline Pen8 & comp & 31 & 203 & 10 & 21.9 & 19.9 & 0.905 \\
\hline Pen10 & comp & 31 & 409 & 40 & 68.7 & 47.7 & 0.695 \\
\hline Pen23 & comp & 30 & 382 & 40 & 75 & 60.6 & 0.808 \\
\hline PN1 & comp & 15 & 175.3 & 5 & 7.2 & 8.4 & 1.15 \\
\hline Pen38 & ext & 73 & 300 & 15 & 107 & -59 & 0.551 \\
\hline Pen43 & ext & 72 & 340 & 28 & 121.1 & -71.1 & 0.587 \\
\hline Pen42 & ext & 70 & 350 & 30 & 133.7 & -78.7 & 0.589 \\
\hline Pen41 & ext & 76 & 266.6 & 6.6 & 82.1 & -46 & 0.561 \\
\hline \multicolumn{8}{|c|}{ Darley Dale sandstone } \\
\hline Dda6 & comp & 36 & 256 & 50 & 97 & 64.7 & 0.667 \\
\hline Dda8 & comp & 35 & 119 & 10 & 23.8 & 19.7 & 0.829 \\
\hline Dda9 & comp & 36 & 164.5 & 20 & 39.5 & 26.9 & 0.68 \\
\hline Dda18 & comp & 36 & 199.5 & 30 & 61.4 & 43.3 & 0.704 \\
\hline Dnn1 & comp & 24 & 95.2 & 5 & 9.2 & 9.4 & 1.02 \\
\hline Dda10 & ext & 78 & 100 & 12 & 30.7 & -19.87 & 0.647 \\
\hline Dda11 & ext & - & 100 & 2.5 & - & - & - \\
\hline Dda12 & ext & - & 60 & 3 & - & - & - \\
\hline Dda13 & ext & 74 & 200 & 27 & 76.18 & -35.5 & 0.466 \\
\hline Dda14 & ext & 74 & 190 & 22.5 & 66.17 & -35.51 & 0.536 \\
\hline Dda15 & ext & 74 & 170 & 21.5 & 55.88 & -32.72 & 0.586 \\
\hline Dda20 & ext & 70 & 250 & 46 & 104.3 & -55.03 & 0.508 \\
\hline Dda21 & ext & 69 & 300 & 58 & 130.04 & -65.24 & 0.502 \\
\hline Dnn2 & ext & 73 & 150 & 20.5 & 63.49 & -26.45 & 0.417 \\
\hline
\end{tabular}


Table 2. Frictional sliding data and saw cut specimens, with an axial displacement rate $=0.05 \mathrm{~mm} \mathrm{~min}^{-1}$. All tests displayed stable sliding. Saw cut angle is measured from cylinder axis. Shear stresses are negative in extension.

\begin{tabular}{|c|c|c|c|c|c|c|c|}
\hline Test \# & Test type & $\begin{array}{l}\text { Shorten/ } \\
\text { extend }\end{array}$ & $\begin{array}{r}\text { Saw cut } \\
\text { angle } \\
\text { (MPa) }\end{array}$ & $\begin{array}{r}\text { Normal } \\
\text { stress } \\
(\mathrm{MPa})\end{array}$ & $\begin{array}{l}\text { Shear } \\
\text { stress }\end{array}$ & $\begin{array}{c}\text { Friction } \\
\text { coeff. }\end{array}$ & Comment \\
\hline \multicolumn{8}{|c|}{ Pennant sandstone } \\
\hline Pa1a1 & Const $\sigma_{n}$ & comp & 45 & 34.4 & 22.4 & 0.651 & \\
\hline Pa1a2 & Const $\sigma_{n}$ & comp & 45 & 71.1 & 44.3 & 0.623 & \\
\hline Pa1b2 & Const $\sigma_{n}$ & comp & 45 & 69 & 45.9 & 0.665 & \\
\hline Pa2a1a & Const $\sigma_{n}$ & comp & 45 & 34.4 & 22.4 & 0.651 & \\
\hline Pa2a1b & Const $\sigma_{n}$ & comp & 45 & 71.1 & 44.3 & 0.623 & \\
\hline $\mathrm{Pa} 2 \mathrm{a} 4$ & Const $\sigma_{n}$ & comp & 45 & 183.5 & 114 & 0.621 & \\
\hline Pa2a5b & Const $\sigma_{n}$ & comp & 45 & 46.8 & 31.5 & 0.595 & \\
\hline $\mathrm{Pa} 2 \mathrm{a} 5 \mathrm{c}$ & Const $\sigma_{n}$ & comp & 45 & 52.9 & 12.8 & 0.601 & \\
\hline $\mathrm{Pa} 3 \mathrm{a}$ & Const $\sigma_{n}$ & comp & 45 & 63.9 & 44 & 0.635 & \\
\hline Pen2 & Const $\sigma_{n}$ & comp & 45 & 35 & 49.2 & 0.711 & \\
\hline Pen2a & Const $\sigma_{n}$ & comp & 45 & 68.5 & 98.4 & 0.696 & \\
\hline Pen $2 b$ & Const $\sigma_{n}$ & comp & 45 & 104.25 & 150.85 & 0.691 & \\
\hline Pen13 & Const $\sigma_{n}$ & comp & 35 & 33.83 & 49.79 & 0.679 & \\
\hline Pen13b & Const $\sigma_{n}$ & comp & 35 & 68.6 & 98.63 & 0.695 & \\
\hline Pala1 & Const $\sigma_{n}$ & ext & 45 & 34.4 & -18.5 & 0.538 & \\
\hline Pa1a2 & Const $\sigma_{n}$ & ext & 45 & 71.1 & -37.3 & 0.525 & \\
\hline Pa1b2 & Const $\sigma_{n}$ & ext & 45 & 69 & -29.25 & 0.424 & \\
\hline Pa2a1a & Const $\sigma_{n}$ & ext & 45 & 34.4 & -18.5 & 0.538 & \\
\hline Pa2alb & Const $\sigma_{n}$ & ext & 45 & 71.1 & -37.3 & 0.525 & \\
\hline Pa2a5a & Const $\sigma_{n}$ & ext & 45 & 46.8 & 22.5 & 0.481 & \\
\hline $\mathrm{Pa} 2 \mathrm{a} 5 \mathrm{~b}$ & Const $\sigma_{n}$ & ext & 45 & 52.9 & -25.1 & 0.474 & \\
\hline $\mathrm{Pa} 2 \mathrm{a} 5 \mathrm{c}$ & Const $\sigma_{n}$ & ext & 45 & 21.3 & -10.1 & 0.474 & \\
\hline $\mathrm{Pa} 3 \mathrm{a}$ & Const $\sigma_{n}$ & ext & 45 & 69.3 & -38.1 & 0.549 & \\
\hline Pen13 & Const $\sigma_{n}$ & ext & 35 & 49.89 & -24.14 & 0.484 & \\
\hline Pen $13 b$ & Const $\sigma_{n}$ & ext & 35 & 98.31 & -55.11 & 0.561 & \\
\hline Pen11g & Const $\sigma_{n}$ & ext & 55 & 37.42 & -16.7 & 0.446 & \\
\hline Pen11b & Const $\sigma_{n}$ & ext & 55 & 73.87 & -35.66 & 0.483 & \\
\hline Pen11 & Const $\sigma_{n}$ & ext & 55 & 113.17 & -50.23 & 0.444 & \\
\hline Pen11d & Const $\sigma_{n}$ & ext & 55 & 49.94 & -18.23 & 0.365 & \\
\hline \multicolumn{8}{|c|}{ Darley Dale sandstone } \\
\hline Dda1 & Const $\sigma_{3}$ & comp & 35 & 34.19 & 23.16 & 0.679 & \\
\hline Dda1b & Const $\sigma_{3}$ & comp & 35 & 67.88 & 45.53 & 0.671 & \\
\hline Dda2a & Const $\sigma_{3}$ & comp & 45 & 55.2 & 35.1 & 0.636 & \\
\hline Dda2b1 & Const $\sigma_{n}$ & comp & 45 & 100.65 & 67.95 & 0.675 & \\
\hline Dda2e & Const $\sigma_{n}$ & comp & 45 & 97.2 & 64.8 & 0.667 & \\
\hline Dda2f & Const $\sigma_{n}$ & comp & 45 & 154.1 & 96.35 & 0.625 & \\
\hline Dda3a & Const $\sigma_{n}$ & comp & 45 & 50 & 36.8 & 0.736 & \\
\hline Dda3b & Const $\sigma_{n}$ & comp & 45 & 101.1 & 67.5 & 0.668 & \\
\hline Dda3c & Const $\sigma_{n}$ & comp & 45 & 151.25 & 93.65 & 0.619 & \\
\hline Dda4a & Const $\sigma_{n}$ & comp & 35 & 49.78 & 34.53 & 0.694 & \\
\hline Dda4c & Const $\sigma_{n}$ & comp & 35 & 49.36 & 35.93 & 0.728 & \\
\hline Dda4e & Const $\sigma_{n}$ & comp & 35 & 99.34 & 68.18 & 0.686 & \\
\hline Dda5a & Const $\sigma_{n}$ & comp & 35 & 91.62 & 59.3 & 0.647 & \\
\hline Dda5c & Const $\sigma_{3}$ & comp & 35 & 94.97 & 64.09 & 0.675 & \\
\hline Dda5e & Const $\sigma_{3}$ & comp & 35 & 180.08 & 114.22 & 0.634 & \\
\hline Dda6 & Const $\sigma_{3}$ & comp & 36 & 97.16 & 64.77 & 0.667 & $\begin{array}{l}\text { new fault } \\
\text { formed }\end{array}$ \\
\hline Dda7 & Const $\sigma_{3}$ & comp & 35 & 90.8 & 58.12 & 0.64 & \\
\hline Dda16 & Const $\sigma_{n}$ & comp & 55 & 50.84 & 33.22 & 0.653 & \\
\hline Dda2b & Const $\sigma_{n}$ & ext & 45 & 55.8 & -24.9 & 0.446 & \\
\hline Dda2c & Const $\sigma_{n}$ & ext & 45 & 101.17 & -46.83 & 0.463 & \\
\hline Dda2d & Const $\sigma_{n}$ & ext & 45 & 99.2 & -49.8 & 0.502 & \\
\hline Dda3c1 & Const $\sigma_{n}$ & ext & 45 & 98.7 & -48.5 & 0.491 & \\
\hline Dda3c2 & Const $\sigma_{n}$ & ext & 45 & 146.75 & -78.35 & 0.534 & \\
\hline Dda4b & Const $\sigma_{n}$ & ext & 35 & 42.2 & -22.18 & 0.526 & \\
\hline Dda4d & Const $\sigma_{n}$ & ext & 35 & 42.85 & -18.93 & 0.442 & \\
\hline Dda5b & Const $\sigma_{3}$ & ext & 35 & 31.1 & -17.57 & 0.565 & \\
\hline Dda5d & Const $\sigma_{3}$ & ext & 35 & 32.05 & -16.68 & 0.52 & \\
\hline
\end{tabular}




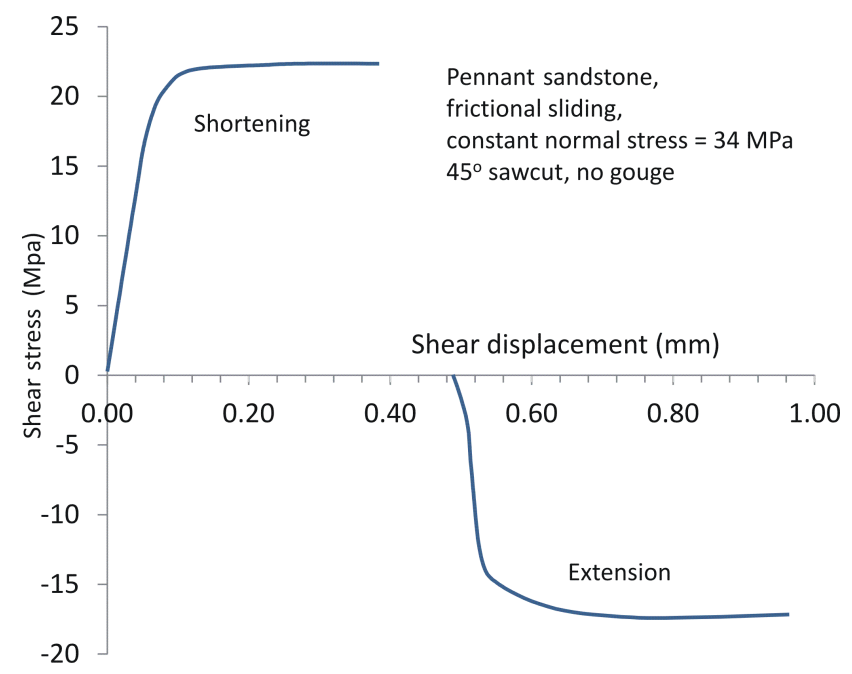

Figure 8. Shear stress versus shear displacement curves for Pennant sandstone sample Pa1a1 saw cut at $45^{\circ}$, sheared at constant normal stress first in shortening and then in extension.

tion coefficients calculated as resolved $\tau / \sigma_{\mathrm{n}}$, irrespective of whether extensional or shortening loading was applied first. Figure 8 shows an example of a specimen of Pennant sandstone alternately sheared in extension and shortening under constant resolved normal stress. After repeated shearing of these relatively smooth, asperity-free surfaces, very little damage to the surface was noted, and there was no significant accumulation of rock flour (fault gouge) on the fault planes. In all tests stable sliding occurred, without stick-slip. No measurements were made of frictional response to sliding velocity stepping.

For some combinations of saw cut angle and rock type, the formation of fresh fault surfaces was observed rather than frictional sliding on an unfavourably oriented saw cut plane. This happens when the cohesive strength of the intact rock is too low. The cohesive strength of Darley Dale sandstone is about $55 \%$ of that of Pennant sandstone; hence Pennant sandstone is better for minimizing this effect. These observations were entirely in accord with expectations from the Mohr-Coulomb description of rock failure and frictional sliding.

Figure 9 shows a compilation of frictional behaviour for both rock types tested both in extension and in shortening, as well as over the range of all three saw cut angles used. Frictional sliding behaviour on faults produced from failure of intact rocks is shown in Figs. 4 and 5 and reproduced for comparison with saw cut data in Fig. 9. For both rock types the coefficient of sliding friction is not influenced by the orientation of the saw cut and is within 2 SD the same as for a freshly faulted surface. It is striking, however, that in all cases the coefficient of sliding friction is smaller in extension than in shortening by about $25 \%$. In shortening, the coefficients of sliding friction for Darley Dale and Pennant sandstones are respectively 0.653 and 0.685 . Combined they are $0.661 \pm 0.007(1 \mathrm{SD})$. In extension they are respectively 0.502 and 0.529 . Combined they are $0.516 \pm 0.007$ ( $1 \mathrm{SD})$.

\section{Discussion of results}

\subsection{Rock failure under polyaxial stresses}

Axisymmetric shortening and extension represent the two end-member stress configurations for polyaxial loading, respectively $\sigma_{2}=\sigma_{3}$ and $\sigma_{2}=\sigma_{1}$. Several studies have been made of rock failure under more general polyaxial stress states, $\sigma_{1} \neq \sigma_{2} \neq \sigma_{3}$ (e.g. Handin et al., 1967; Mogi, 1967, 1971; Kern and Karl, 1969; Reches and Dieterich, 1983; Takahashi and Koide, 1989; Song and Haimson, 1997; Chang and Haimson, 2000; Haimson and Chang, 2000, 2002; Smart, 1995), and there have been many reanalyses of such previously published data in attempts to find the most appropriate failure criterion to describe them (e.g. Colmenares and Zoback, 2002; Al-Ajmi and Zimmerman, 2005, 2006; You, 2009; Kwaśniewski, 2012, 2013) and applications of these criteria to problems such as the estimation of far-field stresses from the analysis of hydraulic fractures and borehole breakouts (e.g. Haimson and Song, 1993; Lee and Haimson, 1993; Ajmi and Zimmerman, 2005, 2006; Colmenares and Zoback, 2002). Failure criteria employed fall into those that are based on attainment of a critical value of a function of stress invariants versus wholly empirical criteria. A given criterion can work well for one rock whilst a different criterion may be better for another rock type.

The compilation and statistical analysis of polyaxial failure data by Colmenares and Zoback (2002) show (a) that for most polyaxial strength data the intermediate principal stress lies closer to $\sigma_{3}$ than to $\sigma_{1}$ and (b) that the applicability of a given criterion would be particularly sensitive to results obtained with $\sigma_{2}=\sigma_{1}$. There are relatively few data available for the strength of brittle rocks under axially symmetric extension $\left(\sigma_{2}=\sigma_{1}\right)$. When there are only axisymmetric compression and extension data available, as in the present study, one may use the axisymmetric compression data for particular generalized failure criteria to predict the axisymmetric extension behaviour using a particular failure criterion and to compare the prediction with the experimental results. For Darley Dale and Pennant sandstones, for example, we compare the predictions of the modified Lade criterion (Lade, 1977; Colmenares and Zoback, 2002) with the Mogi (1967) empirical criterion.

\subsection{The modified Lade criterion}

This is an example of a failure criterion that postulates that failure occurs when some function of the stress invariants reaches a critical value (Lade, 1977; Ewy, 1999):

$\left(I_{1}^{\prime}\right)^{3} / I_{3}=27+\eta$, 

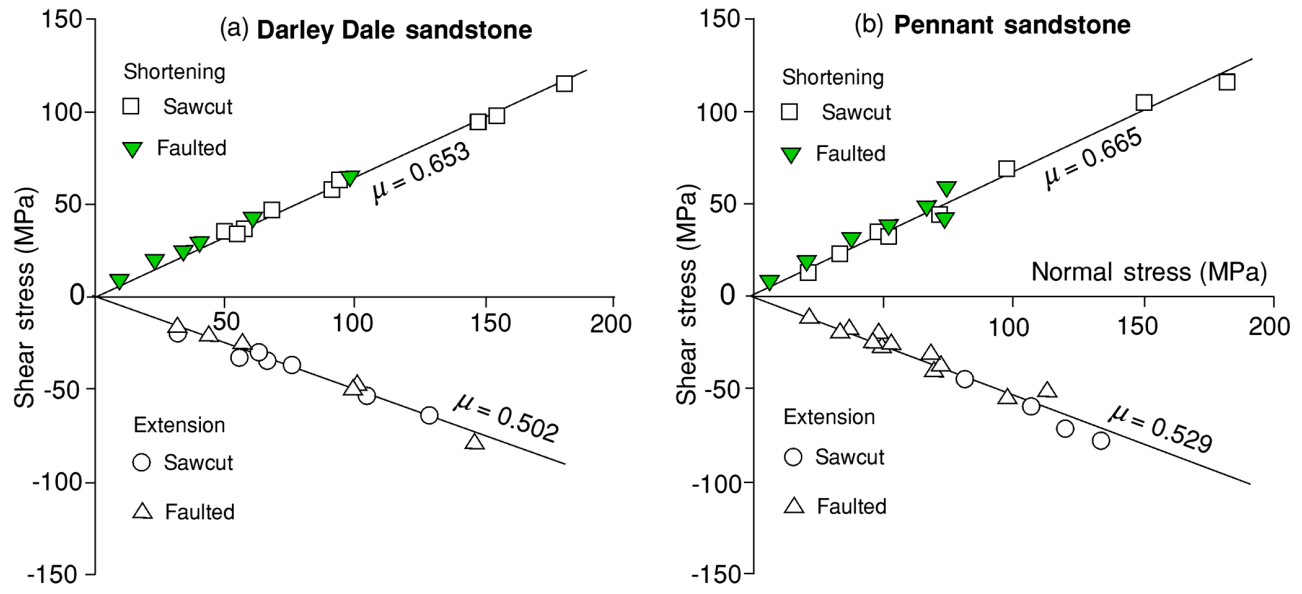

Figure 9. Frictional sliding data on saw cuts (including saw cut angles 35,45 and $55^{\circ}$ to the cylinder axis of the sample) and freshly faulted surfaces for Darley Dale and Pennant sandstones. For both rock types, friction coefficient in shortening is about $25 \%$ greater than in extension.

where

$I_{1}^{\prime}=\left(\sigma_{1}+S\right)+\left(\sigma_{2}+S\right)+\left(\sigma_{3}+S\right) ; \quad I_{3}=\sigma_{1} \sigma_{2} \sigma_{3}$

and

$S=S_{\mathrm{o}} / \tan \varphi ; \eta=4(\tan \varphi)^{2}(9-7 \sin \varphi) /(1-\sin \varphi)$.

$S_{\mathrm{o}}$ is the cohesive strength and $\varphi$ is the angle of internal friction from axisymmetric shortening tests. For each rock type a standard Mohr-Coulomb linear fit to the axisymmetric shortening tests was obtained, of the form

$\sigma_{1}=a+b \sigma_{3}$

in which $a$ is the unconfined compressive strength and $b=(1+\sin \varphi) /(1-\sin \varphi)$. For each of the axisymmetric extension tests performed, the least stress at failure $\left(\sigma_{3}\right.$, the axial stress) was applied to Eq. (1) to find the corresponding value of $\sigma_{1}$ that would apply in an axisymmetric shortening test. These values were then applied to the failure criterion iteratively, keeping $\sigma_{3}$ constant, so that the expected values of $\sigma_{2}=\sigma_{1}$ in the case of axisymmetric extension could be calculated for comparison with the measured values and hence to obtain the expected shape of the failure curve in the polyaxial stress region. The results of these calculations are shown in Fig. 10. The predicted stresses at $\sigma_{2}=\sigma_{1}$ show that failure in extension is expected to occur under higher differential stresses than in shortening, particularly at higher minimum stress values, but the predictions substantially overestimate the observed values for both Pennant sandstone and Darley Dale sandstone.

\subsection{The Mogi (1967) empirical criterion}

Mogi (1967) proposed a modified form of the MohrCoulomb criterion to describe his data in terms of maximum shear stress and a modified expression for the normal stress across the hypothetical failure plane, increased by a fraction $(\beta)$ of $\sigma_{2}$ :

$\left(\sigma_{1}-\sigma_{3}\right) / 2=m\left(\left(\sigma_{1}+\beta \sigma_{2}+\sigma_{3}\right) / 2\right)^{n}$.

$m$ and $n$ are empirically determined parameters that can be found such that the best-fit curves for respectively the shortening and extension data coincide. This has been done for Darley Dale and Pennant sandstones in Fig. 11, and the resultant fits are shown in Fig. 12 in $\sigma_{1}$ versus $\sigma_{2}$ coordinates. This criterion causes failure in extension to occur at a higher differential stress than in shortening, but there is only a minor enhancement of differential stress for intermediate values of $\sigma_{2}$. The values of $\sigma_{2}$ at failure in extension predicted from the compression data correspond quite well with the measured values (Fig. 12).

Data for Shirahama sandstone (Takahashiu and Koide, 1989 ; porosity $=11 \%$, mean grain size $0.15 \mathrm{~mm}$ ), the only data for a porous sandstone reviewed by Colmenares and Zoback (2002) and which might be compared with Darley Dale and Pennant sandstones, are also described quite well by this criterion (Fig. 13). The three fit parameters, $m, \beta$ and $n$, are very similar for all three sandstones. For Shirahama sandstone $m=2.27, n=0.810$ and $\beta=0.06$, and for the other sandstones the values are shown in Fig. 11. The Shirahama sandstone data do not, however, extend as far as either the axisymmetric compression or the axisymmetric extension conditions. In this respect the curves shown are best fits to the failure criterion for the data available and are not precisely of the same significance as the curves shown in Fig. 12. It can be seen that the best-fit curves are imperfect, because the residuals are not uniformly distributed about the individual best-fit curves. Nevertheless, they provide a useful description of the data. 

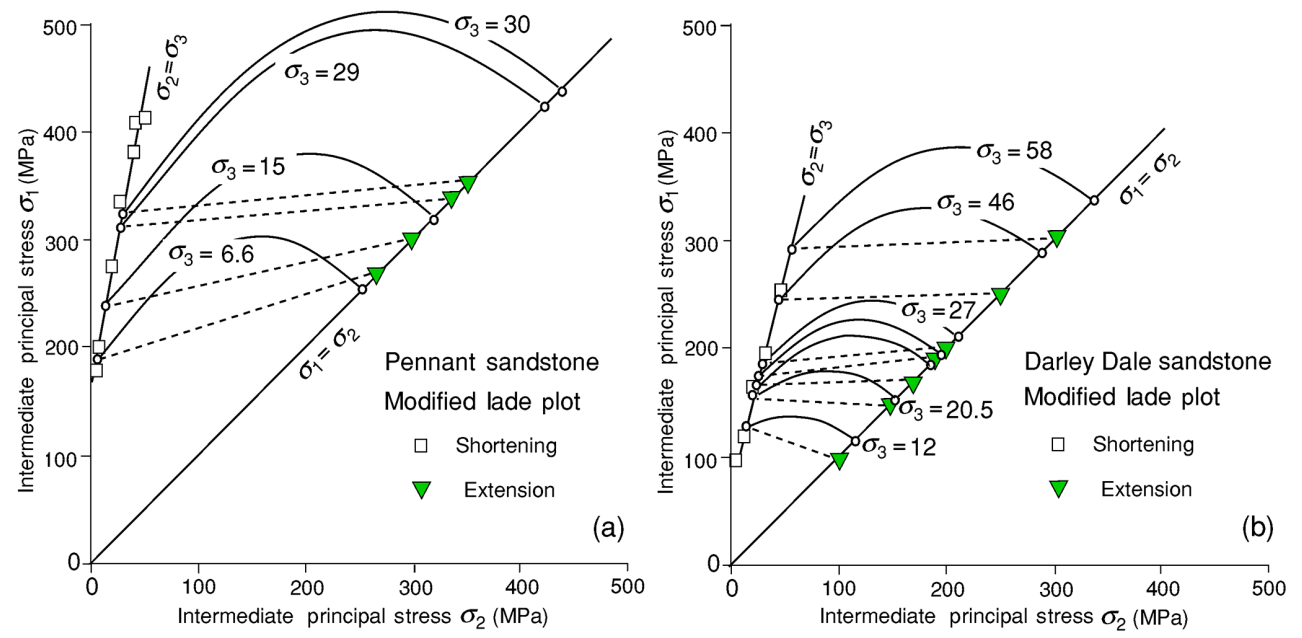

Figure 10. Test of how well the modified Lade polyaxial failure criterion predicts the results of extension tests from the Mohr-Coulomb description of the shortening tests for Pennant and Darley Dale sandstones. Dashed lines link experimental results for specific extension tests to the expected $\sigma_{1}$ values in shortening for the same value of $\sigma_{3}$. For each such value of $\sigma_{3}$ (indicated) the expected failure point in extension is calculated (on the $\sigma_{1}=\sigma_{2}$ line), plus the shape of the failure criterion for intermediate values of $\sigma_{2}$. In both cases the modified Lade criterion overestimates the observed axisymmetric extension result for the higher values of $\sigma_{3}$.

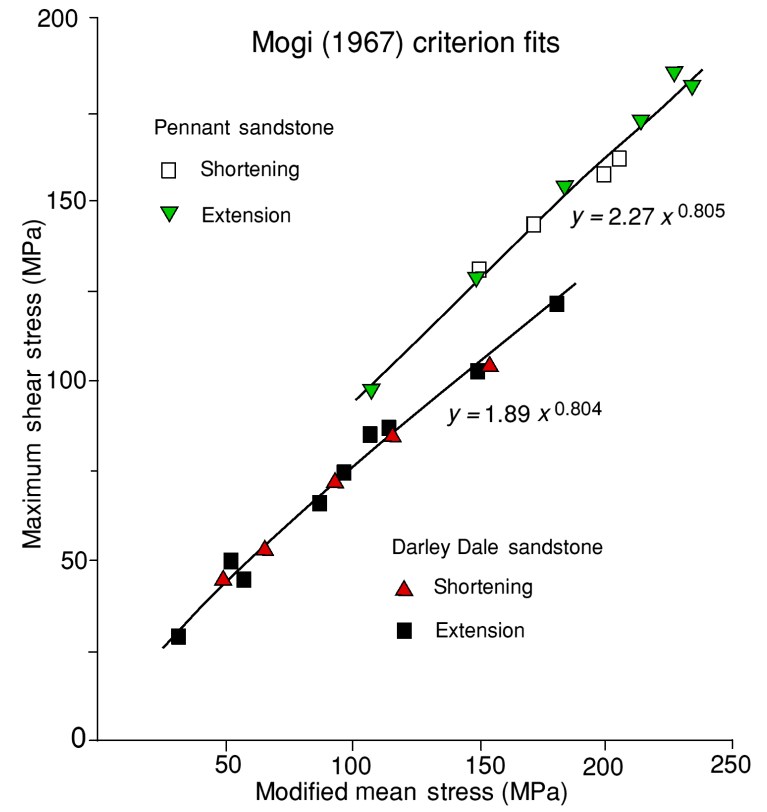

Figure 11. Fits to failure data for Pennant and Darley Dale sandstones for $\beta$ values that bring the shortening and extensional data onto common curves. Maximum shear stress $=\left(\sigma_{1}-\sigma_{3}\right) / 2$ and modified mean stress $=\left(\sigma_{1}+\beta \sigma_{2}+\sigma_{3}\right) / 2$. $\beta$ for Pennant sandstone is 0.09 and for Darley Dale sandstone is 0.01 .

Mogi (1971) also proposed a failure criterion that is a generalization of the von Mises yield criterion:

$\tau_{\mathrm{oct}}=m\left(\left(\sigma_{1}+\sigma_{3}\right) / 2\right)^{n}$, where $\tau_{\text {oct }}$ is the octahedral shear stress. This criterion predicts no strengthening under extensional relative to shortening loading conditions and, depending on the best-fit parameters, can predict two different values of $\sigma_{1}$ for a range of values of $\sigma_{2}$ and $\sigma_{3}$. This is physically impossible and arises because the curves for constant values of $\sigma_{3}$ take the form of inclined ellipse sectors with positive slopes at each end of the $\sigma_{3}$ range. For these reasons we have not explored this criterion further.

\subsection{Role of anisotropy of rock strength}

There has generally been a lack of attention to the possible role of strength anisotropy in the determination of failure criteria under polyaxial stress states. Dehler and Labuz (2007) reported axisymmetric extension and shortening test data for Berea sandstone ( $22 \%$ porosity, acoustic anisotropy at atmospheric pressure $1 \%$ ) at confining pressures up to $5 \mathrm{MPa}$, on samples cut with a cylinder axis both normal and parallel to bedding. Their data did not show any influence of bedding orientation on strength beyond the effects of experimental variability. Nevertheless, for rock types that are significantly mechanically anisotropic it may prove impossible to separate the influence of anisotropy from obtaining a failure criterion. This is because the orthorhombic symmetry of the stress tensor combined with a different symmetry for strength variations arising from anisotropy means that, for example, equivalent tests cannot be carried out, say, in extension and shortening. This is illustrated in Fig. 14 for the case of different forms of transition from axisymmetric shortening normal to bedding to axisymmetric extension, whilst keeping the bedding orientation fixed. This may lead to different forms of 

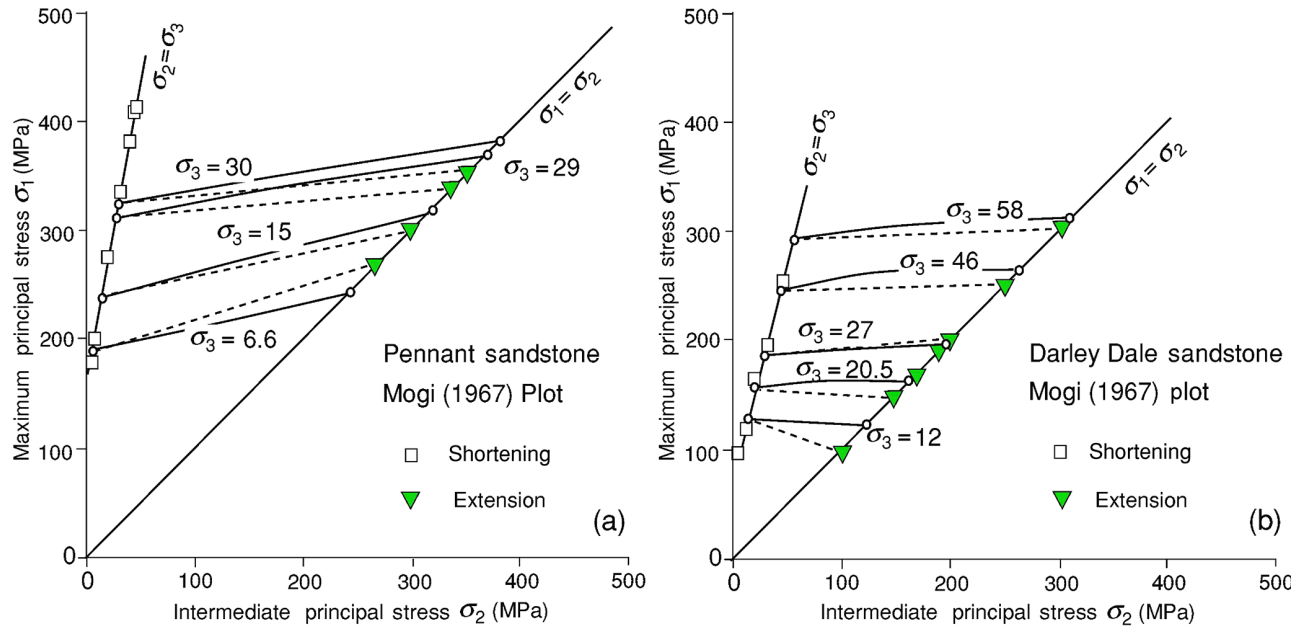

Figure 12. Test of how well the Mogi (1967) polyaxial failure criterion predicts the results of extension tests from the Mohr-Coulomb description of the shortening tests for Pennant and Darley Dale sandstones. Dashed lines link experimental results for specific extension tests (inverted triangles) to the expected $\sigma_{1}$ values in shortening for the same value of $\sigma_{3}$. For each such value of $\sigma_{3}$ (indicated) the expected failure point in extension is calculated (small circles on the $\sigma_{1}=\sigma_{2}$ line), plus the shape of the failure criterion for intermediate values of $\sigma_{2}$. There is a moderately good correspondence.
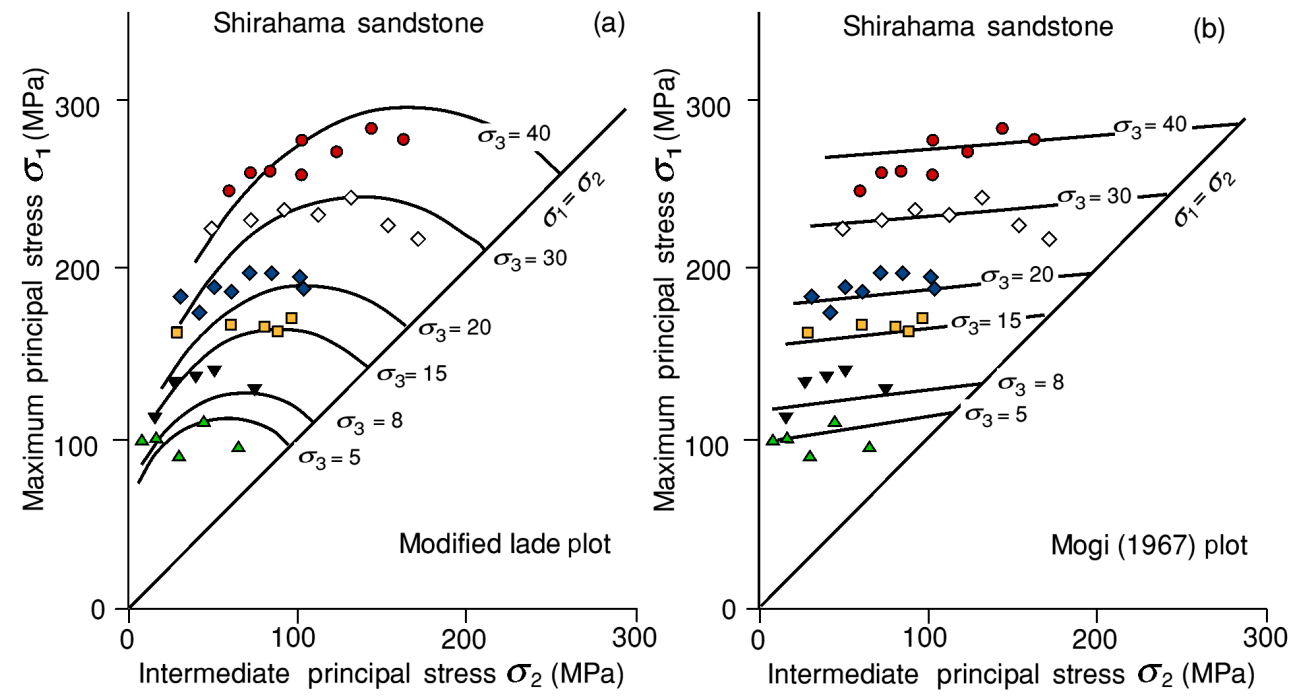

Figure 13. Polyaxial stress data at failure for Shirahama sandstone (Takahashiu and Koide, 1989) fitted by Colmenares and Zoback (2002) to the modified Lade criterion (a) and the Mogi (1967) empirical criterion (b), contoured for the specific $\sigma_{3}$ values shown. The data do not discriminate well between the two criteria, but the Mogi (1967) criterion predicts higher differential stresses for axisymmetric extension, which demonstrates the utility of constraining fits with axisymmetric extension data.

failure criteria being required for different rock types or even for the same rock type.

A further well-known complication arises when rocks are strongly anisotropic and the bedding/foliation plane (weak plane) is variously inclined to the principal stress directions (Jaeger, 1960; Donath, 1961; Smith and Cheatham, 1980; Ambrose 2014). There is a range of bedding/foliation plane orientations with respect to the principal stress orientations such that shear failure with frictional sliding can occur pref- erentially on the weak plane, even under simple loading conditions such as axisymmetric shortening.

\subsection{Rock friction}

\subsubsection{Comparison of sandstone rock friction in shortening with the Byerlee generalization}

The friction sliding coefficient from shortening tests on Darley Dale and Pennant sandstones can be usefully compared 


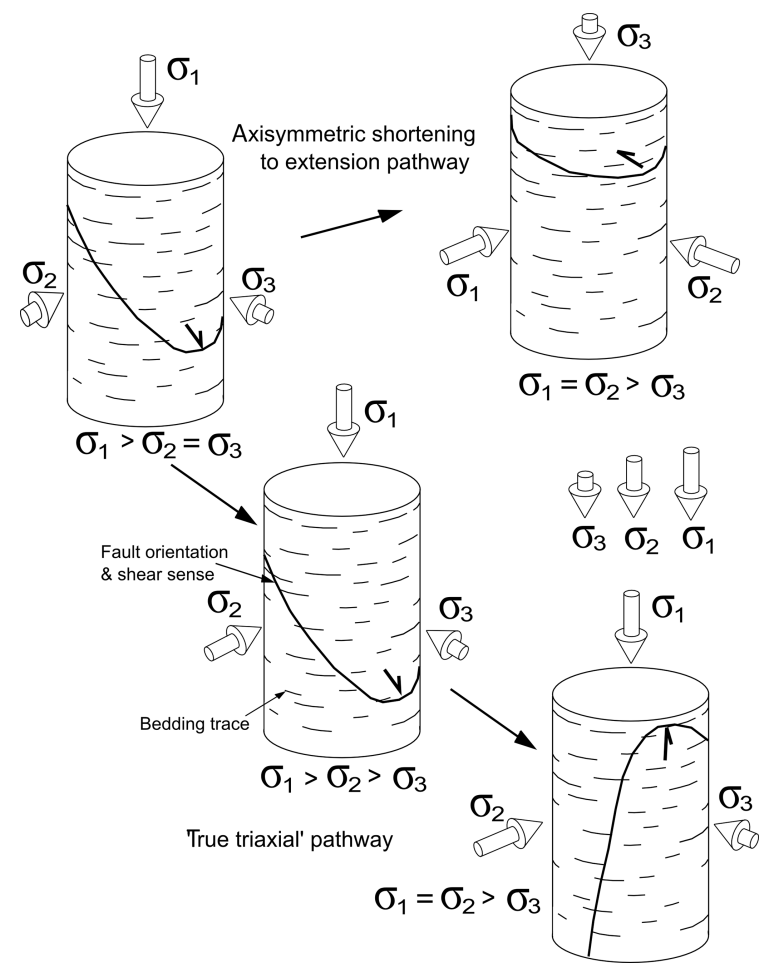

Figure 14. Illustration of different polyaxial loading test sequences for a transversely isotropic rock with constant bedding/foliation orientation. Relative lengths of arrows indicate relative values of principal stresses. Potential fault plane orientations and slip senses are indicated.

Upper pathway corresponds to that used in the present experiments. Axial stress changes from maximum to minimum, and the relative values of the principal stresses change with respect to the transversely isotropic plane.

Lower pathway corresponds to the sequence that might be employed in 'true' triaxial loading. Here, maximum stress can always be normal to the plane of transverse isotropy, but contractional loading is applied across the foliation whereas in the upper path constriction is parallel to the isotropic plane.

with the Byerlee (1978) generalization (often erroneously termed "Byerlee's law") that rock friction is to a useful extent independent of rock type. Figure 1 shows Byerlee's compilation of rock friction data from a wide range of rock types up to a normal stress of $800 \mathrm{MPa}$, leaving out those materials such as swelling clays and talc that are known to have substantially lower friction coefficients. Despite the generalization offered, it is apparent that even Byerlee's compilation shows significant variations in frictional behaviour, especially at low stresses (see also Handin, 1969). At low stresses there are also more data, which increases the likelihood that a greater spread will be observed.

Our friction data for Darley Dale and Pennant sandstones under axisymmetric shortening, together with friction data for other porous sandstones, are also plotted in Fig. 1. These clearly show a tight clustering about a friction coefficient of 0.718 , slightly lower than the 0.779 mean of the Byerlee compiled data fitted to one single friction line. The sandstone data therefore support the Byerlee generalization to a useful extent, which might be applied to the modelling of the behaviour of sandstone reservoirs. Rutter and Glover (2012) also examined sandstone friction in relation to the Byerlee generalization and argued that the critical state line, separating dilatant from compactive cataclastic deformation at high pressures, is equivalent to the friction line.

\subsubsection{Frictional behaviour in axisymmetric shortening and extension tests}

The experimental frictional sliding data in axisymmetric shortening and extensional tests on Darley Dale and Pennant sandstones showed that the friction coefficient is higher in axisymmetric shortening than in extension. This is counterintuitive because friction coefficient is expected to be a 2D concept - the ratio of resolved shear stress in the slip direction to the normal stress acting across the slip plane and hence should not depend upon $\sigma_{2}$. Further, unlike the strengthening effect of increasing $\sigma_{2}$ on intact rock failure strength, the reverse appears to be true for frictional behaviour. It is not wholly clear why this should be, but we can observe that the loading boundary conditions in our axisymmetric extension and shortening tests are not entirely equivalent. The free cylindrical surface of the rock sample is a stress boundary condition because the load is provided by an hydraulic fluid. However, the end load is applied through the loading pistons, and axial strains induced through microcrack dilatation or through the Poisson's ratio effect may modify the end stresses. We postulate that the radial constriction in an extension test modifies the configuration of asperities and fault-parallel, crack-like voids on the slip surface so that the local stresses supporting the axial load are increased to the extent that it becomes easier for the resistance to sliding to be overcome. This happens to a lesser extent in axisymmetric shortening because the constrictional stresses are lower. This is merely a qualitative suggestion, but the phenomenon merits investigation via modelling.

To show how $\sigma_{2}$ relates to $\sigma_{1}$ and $\sigma_{3}$ we can usefully define a ratio $C$ according to $\sigma_{2}=\sigma_{3}+C\left(\sigma_{1}-\sigma_{3}\right)$, from which

$C=\left(\sigma_{2}-\sigma_{3}\right) /\left(\sigma_{1}-\sigma_{3}\right)$.

In the absence of experimental data between the extremes of axisymmetric shortening and extension, the simplest possible assumption is that the friction coefficient $\mu(C)$ varies linearly with $\sigma_{2}$ between $\mu_{1}$ (shortening tests) and $\mu_{2}$ (extensional tests), as shown in Fig. 15a, from which we can write

$\mu(C)=\mu_{1}(1-C)+\mu_{2} C$. 
Sliding will be activated on any weak plane such that for given values of $\sigma_{1}$ and $\sigma_{3}$ and $C$ the orientation of the weak plane plots on the friction line $\mu(C)$.

Jaeger (1964) describes the extension of the Mohr circle construction into $3-\mathrm{D}$. Figure $15 \mathrm{~b}$ shows the relations that exist between the stress state and the frictional sliding line $\tau=\mu(C) \sigma_{\mathrm{n}}$, with an example of one slip plane upon which the stress state $\left(\tau, \sigma_{\mathrm{n}}\right)$ will meet the slip condition. Taking the reference frame to coincide with the principal stress directions $\sigma_{1}, \sigma_{2}$ and $\sigma_{3}$, any slip plane is described by a set of corresponding direction cosines of the normal to the plane, $l=\cos \gamma, m=\cos \lambda$ and $n=\cos \delta$. For convenience, thinking of $\sigma_{1}$ as vertical, $\gamma$ is measured in the vertical plane from $\sigma_{1}$ and the other two angles to the normal to the plane from $\sigma_{2}$ and $\sigma_{3}$ respectively. Resolved maximum shear stress and normal stress $\left(\tau, \sigma_{\mathrm{n}}\right)$ on the slip plane are the coordinates of the point of intersection of the two Mohr circles defined by angles $2 \gamma$ and $2 \delta$, respectively measured from $\sigma_{1}$ and $\sigma_{3}$ in Fig. 15b.

The slip vector is expected to be parallel to the maximum resolved shear stress, thus in general oblique slip is expected in a 3-D stress field. Bott (1955) and Jaeger (1964) derived equations for the resolved dip- and strike-parallel shear stress components, $\tau_{\text {dip }}$ and $\tau_{\text {strike }}$. Expressed in terms of $C$ and $\left(\sigma_{1}-\sigma_{3}\right)$, these are

$$
\begin{aligned}
\tau_{\text {dip }}= & n\left(m^{2} C\left(\sigma_{1}-\sigma_{3}\right)-\left(1-n^{2}\right)\left(\sigma_{1}-\sigma_{3}\right)\right) / \\
& \sqrt{ }\left(l^{2}+m^{2}\right) \\
& \tau_{\text {strike }}=\operatorname{lm} C\left(\sigma_{1}-\sigma_{3}\right) / \sqrt{ }\left(l^{2}+m^{2}\right) .
\end{aligned}
$$

The maximum shear stress $\tau$ is given by $\tau=\sqrt{ }\left(\tau_{\text {dip }}^{2}+\tau_{\text {strike }}^{2}\right)$. The pitch angle $\omega$ between the horizontal on the plane (strike) and the slip vector is given by

$\tan \omega=\tau_{\text {dip }} / \tau_{\text {strike }}=n m C /\left(l\left(m^{2} C-\left(n^{2}+m^{2}\right)\right)\right)$.

In this way the variability of the friction coefficient between different stress regimes can be incorporated to describe slip propensity in a polyaxial stress field.

\subsection{General discussion}

The comparative experimental results in axisymmetric extension and in shortening impact upon the ways in which experimental data are used in modelling brittle rock behaviour for geophysical and rock engineering purposes. The results of axisymmetric shortening tests on rocks to failure, and fitted to a Mohr-Coulomb failure criterion, are widely used in geoengineering under shallow conditions (excavations, tunnelling) and increasingly in hydrocarbon reservoir geomechanics (e.g. Zoback, 2007; Castillo et al., 2000). It is commonly assumed that the 2-D Mohr-Coulomb failure parameters can be applied directly to the prediction of conditions for failure under polyaxial stress states. This should give at least a conservative prediction of initial failure because it ignores the strengthening that arises with increasing mean stress as one moves away from axisymmetric compression conditions, but a more realistic result should be obtained using a polyaxial failure criterion, even if not constrained by true polyaxial or axisymmetric extension test data. Unfortunately, different polyaxial criteria can give widely different predictions, and it seems clear that a given criterion does not apply equally to all rock types, perhaps especially when rocks are anisotropic. However, as we show in Fig. 12, the few porous sandstones for which data are available seem to give consistent results using the Mogi (1967) criterion.

The interpretation of borehole breakouts, analysis of borehole stability and estimation of far-field stresses provide good examples of where the use of a polyaxial failure criterion may be important. Around a vertical borehole wall, according to the Kirsch solution, the circumferential stress varies sinusoidally (e.g. Ewy, 1999; Zoback, 2007). The limits of the width of a borehole breakout can be taken to correspond to the stress state at which failure occurs under stress conditions at the borehole wall. Initial approaches to this problem applied the 2-D Mohr-Coulomb criterion (Barton et al., 1988) assuming the circumferential stress at the onset of failure corresponded to the axisymmetric, unconfined compressive strength. It was quickly realized that the uniaxial compressive strength would underestimate the strength of the borehole wall and that a polyaxial failure criterion was required (Vernik and Zoback, 1992). The vertical stress parallel to the borehole wall is due largely to the depth of burial but is modulated by the circumferential stress through the Poisson ratio effect so that it too varies sinusoidally around the borehole wall. There may also be a radial non-zero stress component arising from mud weight, and its influence will vary according to whether or not the rock permeability allows the fluid to enter the rock pores. Thus the mean stress in the rock adjacent to the borehole wall is greater than it would be if it arose only from the circumferential stress.

Song and Haimson (1997) demonstrated experimentally for two rock types how a polyaxial failure criterion could estimate better the stress state in the borehole wall and hence provide an improved estimate of the far-field maximum insitu stress. Unfortunately, the most appropriate polyaxial criterion to use varies with rock type, and in the absence of any experimental constraints it may not be self-evident which is the best one to use. However, as we demonstrate above, for porous sandstones the Mogi (1967) criterion may be generally useful and is simple to apply.

The stress conditions for the onset of frictional sliding are commonly taken to impose a bound on the load bearing capacity of rock masses, whether it be fractured and jointed rock encountered in geoengineering or modelling the behaviour of the Earth's upper crust. The results presented here suggest that the frictional behaviour assumed should be modified according to the nature of the stress state, at least for porous sandstones. Under constrictional (extensional) load- 

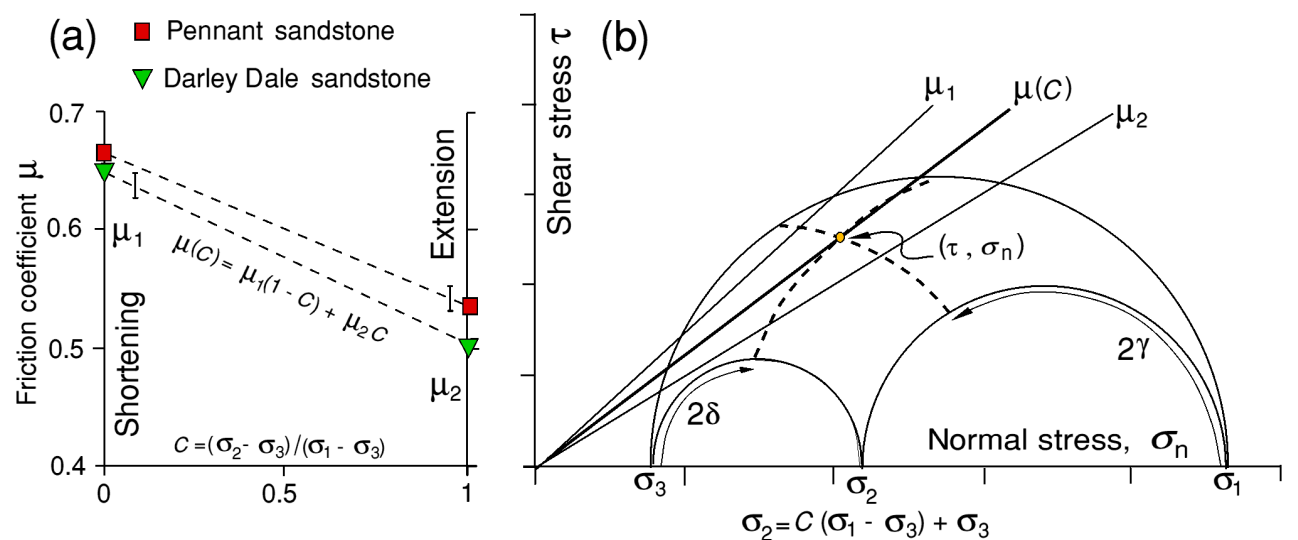

Figure 15. (a) Comparison of friction coefficients for Darley Dale and Pennant sandstones sheared in extension and shortening modes. The simplest assumption is that there is a linear variation of friction coefficient between the extremes shown. (b) Three-dimensional Mohr circle construction (no stress scales) to show how a general friction coefficient lies between the extremes of $\mu_{1}$ (shortening) and $\mu_{2}$ (extensional) loading. For a specified position of the intermediate principal stress $\sigma_{2}=C\left(\sigma_{2}-\sigma_{3}\right) /\left(\sigma_{1}-\sigma_{3}\right)$, there will be a particular friction coefficient $\mu(C)$, along which combinations of resolved shear and normal stress corresponding to direction angles $\delta$ and $\gamma$ will give rise to sliding.

ing (high $C$ value), the frictional strength can be lowered by more than $20 \%$ relative to axisymmetric shortening; hence the Mohr-Coulomb criterion may significantly overestimate rock mass stability for reactivation of pre-existing planes of weakness. The more conservative value of frictional coefficient should perhaps be used, but it is presently unclear whether the appropriate value of friction coefficient will be influenced by the nature of the boundary constraints applied to the rock mass and what the influence of rock type will be.

\section{Conclusions}

Darley Dale and Pennant sandstones were tested under conditions of both axisymmetric shortening and extension normal to bedding, corresponding to the two extremes of loading under polyaxial stress conditions. The intact rock strengths for the sandstones studied are best reconciled using the Mogi (1967) criterion for failure under general triaxial conditions:

$\left(\sigma_{1}-\sigma_{3}\right) / 2=m\left(\left(\sigma_{1}+\beta \sigma_{2}+\sigma_{3}\right) / 2\right)^{n}$.

The parameters $m, \beta$ and $n$ are very similar in value for at least three different porous sandstones.

Failure under generalized stress conditions can be predicted from a knowledge of the Mohr-Coulomb failure criterion under axisymmetric compression conditions provided the best form of the polyaxial failure criterion is known. Unfortunately, a single generalized failure criterion does not appear to apply equally to all rock types. Nevertheless, where possible the appropriate polyaxial failure criterion should be used for engineering and other modelling applications.

The orientations of the fault planes produced are radically different with respect to the maximum compression direction in the two loading conditions studied. The normal to the
Mohr-Coulomb failure envelope does not in either case predict the orientation of the fault planes that are eventually produced.

Frictional sliding on variously inclined saw cuts and failure surfaces produced in intact rock samples was also investigated. Friction coefficient is not affected by fault plane orientation in a given loading configuration, but friction coefficients in axisymmetric extension were systematically lower than in axisymmetric shortening. This effect may also apply to general intermediate stress states $\left(\sigma_{1} \neq \sigma_{2} \neq \sigma_{3}, 0<C<1\right)$ and for the present it is assumed that friction coefficient varies linearly with $C$.

Friction data for these and other porous sandstones in axisymmetric shortening accord well with the Byerlee (1977) generalization about rock friction being largely independent of rock type. For engineering and geodynamic modelling purposes the stress-state-dependent friction coefficient should be used for sandstones. It is not known to what extent this finding might apply to other rock types.

Acknowledgements. This work was carried out whilst Abigail Hackston was in receipt of a NERC research studentship. We are grateful to Experimental Officer Steve May for equipment maintenance and help with the development of techniques. Kate Brodie carried out the scanning electron microscope imaging of samples. We appreciate the helpful and constructive reviews provided by Tom Blenkinsop and Albert Griera.

Edited by: F. Bastida 


\section{References}

Al-Ajmi, A. M. and Zimmerman, R. W.: Relation between the Mogi and the Coulomb failure criteria, Int. J. Rock Mech. Min., 42, 431-439, 2005.

Al-Ajmi, A. M. and Zimmerman, R. W.: Stability analysis of vertical boreholes using the Mogi-Coulomb failure criterion, Int. J. Rock Mech. Min., 43, 1200-1211, 2006.

Ambrose, J.: Failure of Anisotropic Shales under Triaxial Stress Conditions, unpublished $\mathrm{PhD}$ thesis, Imperial College London, 265 pp., 2014.

Barton, C. A., Zoback, M. D. and Burns, K. L.: In-situ stress orientation and magnitude at the Fenton geothermal site, New Mexico, determined from wellbore breakouts, Geophys. Res. Lett., 15, 467-470, 1988.

Bernabé, Y., Mok, U., and Evans, B.: A note on the oscillating flow method for measuring rock permeability, Int. J. Rock Mech. Min., 43, 311-316, 2006.

Bott, M. H. P.: The mechanics of oblique slip faulting, Geol. Mag., 96, 109-117, 1959.

Byerlee, J. D.: Brittle-ductile transition in rocks, J. Geophys. Res., 73, 4741-4750, 1968.

Byerlee, J. D.: Friction of rocks, Pure Appl. Geophys., 116, 615626, 1978.

Castillo, D., Bishop, D. J., Donaldson, I., Kuek, D., de Ruig, M., Trupp, M., and Shuster, M. W.: Trap integrity in the Laminaria high-Nancar trough region, Timor Sea: prediction of fault seal failure using well-constrained stress tensors and fault surfaces interpreted from 3D seismics, Appea J., 40, 151-173, 2000.

Chang, C. and Haimson, B.: True triaxial strength and deformability of the KTB deep hole amphibolite, J. Geophys. Res., 105, 18999-19013, 2000.

Colmenares, L. B. and Zoback, M. D.: A statistical evaluation of intact rock failure criteria constrained by polyaxial test data for five different rocks, Int. J. Rock Mech. Min., 39, 695-729, 2002.

Dehler, W. and Labuz, J. F.: Stress Path Testing of an Anisotropic Sandstone, J. Geotech. Geoenviron., 133, 116-119, 2007.

Donath, F. A.: Experimental study of shear failure in anisotropic rocks, Geol. Soc. Am. Bull., 72, 985-990, 1961

Ewy, R.: Wellbore-stability predictions by use of a modified Lade criterion, SPE Drill. Completion, 14, 85-91, 1999.

Goetze, C. and Evans, B.: Stress and temperature in the bending lithosphere as constrained by experimental rock mechanics, Geophys. J. Roy. Astr. S., 59, 463-478, 1979.

Haimson, B. C. and Chang, C.: A New true triaxial cell for testing mechanical properties of rock, and its use to determine rock strength and deformability of Westerly Granite, Int. J. Rock Mech. Min., 36, 285-296, 2000.

Haimson, B. and Chang, C.: True triaxial strength of the KTB amphibolite under borehole wall conditions and its use to estimate the maximum horizontal in situ stress, J. Geophys. Res., 107, 2257-2271, 2002.

Haimson, B. and Rudnicki, J. W.: The effect of the intermediate principal stress on fault formation and fault angle in siltstone, $\mathrm{J}$. Struct. Geol., 32, 1701-1711, 2010.

Haimson, B. C. and Song, I.: Laboratory study of borehole breakouts in Cordova Cream: a case of shear failure mechanism, Int. J. Rock Mech. Min., 30, 1047-1056, 1993.

Handin, J.: On the Coulomb-Mohr Failure Criterion, J. Geophys. Res., 74, 5343-5348, 1969.
Handin, J., Heard, H. C., and Magouirk, J. N.: Effect of the intermediate principal stress on the failure of limestone, dolomite, and glass at different temperature and strain rate, J. Geophys. Res., 72, 611-640, 1967

Heap, M. J., Baud, P., Meredith, P. G., Bell, A. F., and Main, I. G.: Time-dependent brittle creep in Darley Dale sandstone, J. Geophys. Res., 114, B07203, doi:10.1029/2008JB006212, 2009.

Heard, H. C.: Transition from brittle fracture to ductile flow in Solenhofen limestone as a function of temperature, confining pressure and interstitial fluid pressure, edited by: Handin, J. and Griggs, D. T., Rock Deformation, Geol. Soc. Am. Mem., 79, 193-226, 1960.

Heard, H. C.: Effect of large changes in strain rate in the experimental deformation of Yule marble, J. Geol., 71, 162-195, 1963.

Heard, H. C.: Steady state flow in polycrystalline halite at pressures of 2 kilobars, in: Flow and Fracture of Rocks, Geophys. Monogr. Ser., vol. 16, edited by: Heard, H. C., Borg, I. Y., Carter, N. L., and Raleigh, C. B., AGU, Washington, DC, 191-190, 1972.

Jaeger, J. C.: Shear failure of anisotropic rock, Geol. Mag., 97, 6572,1960

Jaeger, J. C.: Elasticity, fracture and flow, Methuen and Co., London, 212 pp., 1964.

Kelling, G.: Upper Carboniferous sedimentation in South Wales, in: The Upper Palaeozoic and Post-Palaeozoic Rocks of Wales, edited by: Oven, T. R., University of Wales Press, Cardiff, 185224, 1974.

Kern, H. and Karl, F.: Eine dreiaxial wirkended Gesteinspresse mit Heizvorrichtung, Bergbauwissenschaflen, 16, 90-92, 1969.

Kohlstedt, D. L., Evans, B., and Mackwell, S. J.: Strength of the lithosphere: constraints imposed by laboratory experiments, J. Geophys. Res., 100, 17587-17602, 1995.

Kwaśniewski, M.: Mechanical behaviour of rocks under true triaxial compression - a review, in: True triaxial testing of rocks, edited by: Kwaśniewski, M., Li, X., and Takahashi M., Chapter 8, Geomechanics Research Series 4, CRC Press, Taylor \& Francis Group, Leiden Holland, 99-138, 2012.

Kwaśniewski, M.: Recent advances in studies of the strength of rocks under true triaxial compression conditions, Arch. Min. Sci., 58, 1177-1200, 2013

Lade, P.: Elasto-plastic stress-strain theory for cohesionless soil with curved yield surfaces, Int. J. Solids Struct., 13, 1019-1035, 1977.

Lee, M. and Haimson, B.: Laboratory study of borehole breakouts in Lac du Bonnet granite: a case of extensile failure mechanism, Int. J. Rock Mech. Min., 30, 1039-1046, 1993.

Mackwell, S. J. and Paterson, M. S.: New developments in deformation studies: high-strain deformation, in: Plastic deformation of minerals and rocks, edited by: Karato, S. I. and Wenk, H. R., Rev. Mineral. Geochem., 51, 1-19, 2002.

Mair, K. and Marone, C.: Friction of simulated fault gouge for a wide range of velocities and normal stresses, J. Geophys. Res., 104, 28899-28914, 1999.

Menéndez, B., Zhu, W., and Wong, T.: Micromechanics of brittle faulting and cataclastic flow in Berea sandstone, J. Struct. Geol., 18, 1-16, 1996.

Mogi, K.: Effect of the intermediate principal stress on rock failure, J. Geophys. Res., 72, 5117-5131, 1967.

Mogi, K.: Fracture and flow of rocks under high triaxial compression, J. Geophys. Res., 76, 1255-1269, 1971. 
Numelin, T., Marone, C., and Kirby, E., Frictional properties of a natural fault gouge from a low-angle normal fault, Panamint valley, California, Tectonics, 26, TC2004, doi:10.1029/2005TC001916, 2007.

Reches, Z. and Dieterich, J. H.: Faulting of rocks in threedimensional strain fields, I. failure of rocks in polyaxial, servocontrol experiments, Tectonophysics, 95, 111-132, 1983.

Rutter, E. H. and Glover, C. T.: The deformation of porous sandstones; are Byerlee friction and the critical state line equivalent?, J. Struct. Geol., 44, 129-140, 2012.

Scott, T. E. and Nielsen, K. C.: The effects of porosity on the brittleductile transition in sandstones, J. Geophys. Res., 96, 405-414, 1991a.

Scott, T. E. and Nielsen, K. C.: The effects of porosity on fault reactivation in sandstones, J. Geophys. Res., 96, 2353-2362, 1991 b.

Smart, B. G. D.: A true triaxial cell for testing cylindrical rock specimens, Int. J. Rock Mech. Min., 32, 269-275, 1995.

Smith, M. B. and Cheatham, J. B.: A Three-Dimensional Anisotropic Yield Condition for Green River Shale, J. En. Resour. Technol., 102, 184-189, 1980.

Song, I. and Haimson, B. C.: Polyaxial strength criteria and their use in estimating in-situ stress magnitudes from borehole breakout dimensions, Int. J. Rock Mech. Min., 34, 3-4, 1997.
Takahashi, M. and Koide, H.: Effect of the intermediate principal stress on strength and deformation behavior of sedimentary rocks at the depth shallower than $2000 \mathrm{~m}$, edited by: Maury, V. and Fourmaintraux, D., Rock at great depth, vol. 1, Rotterdam, Balkema, 19-26, 1989.

Vernik, L. and Zoback, M. D.: Estimation of maximum horizontal principal stress magnitude from stress-induced well bore breakouts in the Cajon Pass scientific research borehole, J. Geophys. Res., 97, 5109-5119, 1992.

You, M. Q.: True-triaxial strength criteria for rock, Int. J. Rock Mech. Min., 46, 115-127, 2009.

Zhang, L.: A generalized three-dimensional Hoek-Brown strength criterion, Rock Mech. Rock Eng., 41, 893-915, 2008.

Zhu, W. and Wong, T.-F.: The transition from brittle faulting to cataclastic flow: permeability evolution, J. Geophys. Res., 102, 3027-3041, 1997.

Zoback, M.: Reservoir Geomechanics, Cambridge University Press, Cambridge, UK, 449 pp., 2007. 